\title{
Seleção de ovinos geneticamente resistentes ao scrapie
}

\author{
Cristina Santos Sotomaior * \\ Fernanda Trentini Lopes Ribeiro \\ Rüdiger Daniel Ollhoff \\ PPG em Ciência Animal, Escola de Ciências Agrárias e Medicina Veterinária \\ Pontifícia Universidade Católica do Paraná \\ BR 376 Km 14, CEP 83010-500, São José dos Pinhais - PR, Brasil \\ * Autor para correspondência \\ cristina.sotomaior@pucpr.br
}

Submetido em 12/04/2012

Aceito para publicação em 07/08/2012

\section{Resumo}

A susceptibilidade dos ovinos ao scrapie está relacionada a polimorfismos do gene da proteína priônica celular (PRNP). Polimorfismos nos códons 136 (alanina, A/ valina, V), 154 (arginina, R/ histidina, H) e 171 (glutamina, Q/ arginina, R/ histidina, H) são os principais determinantes de susceptibilidade/resistência ao scrapie clássico. Eles são combinados em 4 principais variantes do alelo ancestral ARQ: VRQ, AHQ, ARH e ARR. Programas de melhoramento genético na União Europeia e Estados Unidos têm utilizado como estratégia selecionar o alelo resistente ARR, diminuindo a frequência do alelo susceptível VRQ em populações de ovinos. No Brasil, há poucos dados de genotipagem do gene PRNP e, até o momento, nenhum tipo de controle baseado em cruzamentos direcionados foi implementado. Esta revisão focará aspectos importantes como epidemiologia e resistência genética, como ferramenta de programas de controle de scrapie.

Palavras-chaves: Genotipagem; Ovinos; Polimorfismo; Proteína priônica celular; Scrapie

\section{Abstract}

Selective breeding for scrapie resistance in sheep. It is well known that the susceptibility of sheep to scrapie is determined by the host's prion protein gene (PRNP). PRNP polymorphisms at codons 136 (alanine, A/ valine, V), 154 (histidine, H/arginine, R) and 171 (glutamine, Q/histidine, H/arginine, R) are the main determinants of sheep susceptibility/resistance to classical scrapie. There are four major variants of the wild-type ARQ allele: VRQ, AHQ, ARH and ARR. Breeding programs have been developed in the European Union and the USA to increase the frequency of the resistant ARR allele while decreasing the frequency of the susceptible VRQ allele in sheep populations. In Brazil, little PRNP genotyping data are available for sheep, and thus far, no controlled breeding scheme for scrapie has been implemented. This review will focus on important epidemiological aspects of scrapie and the use of genetic resistance as a tool in breeding programs to control the disease.

Key words: Cellular prion protein; Genotyping; Polymorphism; Scrapie; Sheep 


\section{Introdução}

Scrapie faz parte das Encefalopatias Espongiformes Transmissíveis (ETT), que são um grupo de doenças neurodegenerativas, e tem como principal característica o acúmulo de uma isoforma patológica da proteína priônica normal do hospedeiro no Sistema Nervoso Central (SNC) e tecido linforreticular (baço, tonsilas e linfonodos) (HUNTER, 1997; PRUSINER, 1998; HARRIS, 1999).

A proteína priônica ( $\mathrm{PrP})$, na sua forma anormal, também denominada prion, foi descoberta durante estudos experimentais com roedores (PRUSINER, 1982). Diferente das doenças infecciosas clássicas, provenientes de bactérias e vírus, o prion não é codificado por um ácido nucléico extrínseco, mas por genes primários do genoma (MASTRANGELO; WESTAWAY, 2001). A ausência de intermediários para desenvolver a doença, sugeriu a existência de duas isoformas: $\mathrm{PrP}^{\mathrm{C}}$ e $\operatorname{PrP}^{\mathrm{Sc}}$ (CAUGHEY et al., 1991). Eventos ocorridos após a tradução da proteína seriam responsáveis pelas diferenças entre a isoforma celular $\left(\mathrm{PrP}^{\mathrm{C}}\right)$ e a isoforma relacionada à doença $\left(\mathrm{PrP}^{\mathrm{Sc}}-\mathrm{PrP}\right.$ Scrapie $)$.

A via oral é considerada o principal meio de infecção e a transmissão ocorre principalmente no parto e no período pós-parto imediato (DETWILER; BAYLIS, 2003). A transmissão do agente acontece de forma natural, porém o modo de transmissão da doença ainda não é conhecido em todos os detalhes (RYDER et al., 2004). Os sinais clínicos variam conforme a região cerebral afetada e o desenvolvimento é lento e progressivo. O sinal mais visível é a mudança de comportamento e temperamento do animal dentro do seu ambiente de convívio. Há outros sinais secundários, que podem incluir aparente confusão e separação do rebanho, além de distúrbios neurológicos caracterizados por sinais de prurido e ataxia ou falta de coordenação no andar (OIE, 2009; OLLHOFF; SOTOMAIOR, 2011).

Historicamente, a ausência de diagnóstico antemorten de animais infectados dificultava o controle da disseminação da doença (HOINVILLE, 1996). Atualmente, são considerados animais com diagnóstico para scrapie os ovinos e caprinos com resultado positivo à prova de imunohistoquímica (IHQ) em amostras de tecido nervoso ou linfóide (BRASIL, 2008), que inclui, portanto, o diagnóstico a partir de biópsias de terceira pálpebra, tonsilas (VAN KEULEN et al., 1996; O'ROURKE et al., 1998; 2000; JEFFREY et al., 2001) e mais recentemente tecido linfóide associado à mucosa reto-anal (GONZÁLEZ et al., 2005; 2006; 2008a; 2008b).

Inicialmente, como a ocorrência do scrapie era conhecida por estar associada a certas linhagens de ovinos, chegou a ser considerada como uma doença genética e não infecciosa. Atualmente, é definida como uma doença infecciosa e se aceita que um animal para desenvolver a doença deve ser exposto ao agente e ter predisposição genética (STEVENS et al., 2009).

Polimorfismos no gene da proteína priônica celular (PRNP) estão associados a diferenças de susceptibilidade ao agente infeccioso (GOLDMANN et al., 1990; HUNTER et al., 1997a; 1997b; DAWSON et al., 1998). A suscetibilidade do genótipo ARR/ARR aos agentes causadores do scrapie clássico é extremamente baixa, porém não mais considerada nula desde os primeiros casos comprovados de animais ARR/ARR infectados (GROSCHUP et al., 2007). Por outro lado, o alelo VRQ é associado à alta susceptibilidade no desenvolvimento da doença (HUNTER et al., 1997a; 1997b; ELSEN et al., 1999; ACÍN et al., 2004; BILLINIS et al., 2004).

Os programas baseados em seleção de animais geneticamente resistentes ao agente oferecem uma nova perspectiva de estratégias de controle e foram escolhidos por muitos países, como por exemplo, o National Scrapie Plan (NSP) da Grã-Bretanha (DEFRA, 2003) e o The National Genetics Based Flock Clean-up Plan dos Estados Unidos (APHIS, 2005).

Esta opção pela seleção de animais geneticamente resistentes a doenças é uma das alternativas mais interessantes na produção moderna, visto que diminui custos com tratamentos, melhora a condição de bemestar dos animais, além de ser mais sustentável do ponto de vista ambiental. Atualmente, em ovinos, há várias doenças em que é possível a seleção para resistência: scrapie, foot-rot, mastite, paratuberculose, dermatofilose, salmonelose, nematodioses e míiase cutânea (BISHOP; MORRIS, 2007). 
Toda a característica, porém, para poder ser utilizada como critério de seleção para cruzamentos tem que estar baseada num fundamento genético. Segundo Bishop (2006), se a doença não está presente, não se pode dizer se um animal é resistente ou não. Ainda que numerosos trabalhos demonstrem a relação genótipo e resistência/ susceptibilidade a scrapie, muitos dados evidenciam as diferenças que há entre raças e rebanhos, deixando claro que os critérios para a seleção não necessariamente podem e devem ser aplicados igualmente para ovinos de diferentes raças, rebanhos ou países (ACÍN et al., 2004; LÜHKEN et al., 2004).

O objetivo desta revisão é abordar a situação atual da doença, principalmente dos programas de seleção de animais geneticamente resistentes, baseados na genotipagem do gene da proteína priônica celular.

\section{Epidemiologia}

Scrapie foi descrito pela primeira vez em 1732 (DETWILER; BAYLIS, 2003). Inicia-se de forma insidiosa e pode não ser percebido nos rebanhos afetados. O scrapie é encontrado em muitos países produtores de ovinos e os relatos de ausência da doença precisam ser analisados com cuidado. Poucos países com ovinocultura de importância econômica, como Austrália e Nova Zelândia, são considerados livres da ocorrência desta enfermidade (DAWSON et al., 2008). Também há ocorrência natural da doença em caprinos nos Estados Unidos, Canadá, Chipre, Finlândia, Grécia, Itália, Áustria e Inglaterra (DETWILER; BAYLIS, 2003).

No Brasil, a doença foi introduzida pela importação, em 1978, de ovinos Hampshire Down provenientes de rebanhos infectados da Inglaterra (FERNANDES et al., 1978), e posteriormente por um episódio em 1985 no Estado do Paraná, também de ovinos importados do Reino Unido. Estes animais ainda estavam em período de quarentena e, na oportunidade, foram tomadas todas as medidas de emergência sanitária, entre estas a destruição de todos os animais doentes, seus descendentes e contatos. Entre os anos de 1991 e 1996, cerca de 2267 novos ovinos foram importados para o país, e a grande maioria era proveniente dos Estados Unidos (OJEDA; OLIVEIRA, 1998), onde a doença é considerada endêmica. Há registro de casos de scrapie nas raças Hampshire Down e Suffolk vindos do Canadá e da América do Norte (RIBEIRO;

TABELA 1: Casos de scrapie ocorridos no Brasil desde o primeiro relato em 1978, segundo a raça afetada, país de procedência dos ovinos e Estado onde a doença foi diagnosticada.

\begin{tabular}{cccc}
\hline Ano & Raça & Procedência & Estado \\
\hline 1978 & Hampshire Down & Reino Unido & RS \\
$1985^{*}$ & Wiltshire Horn & Reino Unido & PR \\
1995 & Suffolk & USA & PS \\
1997 & Suffolk & USA & PR \\
2001 & Hampshire Down & Canadá & PR \\
$2003^{* *}$ & Hampshire Down & Brasil & MG \\
2005 & & & PR \\
2005 & & & MS \\
2006 & Hampshire Down & Brasil & RS \\
2006 & Suffolk & Brasil & MT \\
$2007^{* * *}$ & Santa Inês & & MT \\
$2007^{* * *}$ & caprino & & MS \\
2008 & & & SP \\
2008 & & Canadá & SP \\
2009 & & USA & PR \\
2010 & & & Bil;
\end{tabular}

Fonte: Adaptado de RIBEIRO et al. (2007) e dados da OIE, disponíveis em www.oie.int. * Primeira notificação oficial no Brasil; ** Primeira notificação em ovino nativo, considerado o primeiro caso autóctone, *** Primeira notificação em caprino e ovino da raça Santa Inês. 
RODRIGUES, 2001), além de vários outros casos reportados na literatura (RIBEIRO, 1996; RIBEIRO et al., 2007) ou notificados na Organização Mundial da Saúde Animal (OIE) (Tabela 1). O caso ocorrido em 2003 no Paraná, no setor de Ovinocultura da PUC-PR, foi considerado o primeiro caso autóctone do Brasil (POHL DE SOUZA et al., 2005).

\section{Resistência genética}

Polimorfismos em nucleotídeos únicos (SNPs), que codificam a sequência do PRNP e resultam em uma mudança no aminoácido, têm sido associado ao scrapie em ovinos, bem como, sua progressão (HUNTER et al., 1989; 1997a; 1997b; GOLDMANN et al. 1990).

Nos ovinos, o gene PRNP possui sequência codificante completa de 771 nucleotídeos, codificando uma proteína precursora de 256 aminoácidos (LEE et al., 1998). Os três códons mais importantes associados com a susceptibilidade em ovinos codificam aminoácidos nas posições 136 (alanina(A)/valina(V)), 154 (arginina(R)/ histidina $(\mathrm{H})$ ) e 171 (glutamina $(\mathrm{G}) / \operatorname{arginina}(\mathrm{R}) /$ histidina $(\mathrm{H}))$. Combinações destes polimorfismos resultam em cinco alelos: ARQ (alanina/arginina/ glutamina), VRQ (valina/arginina/glutamina), AHQ (alanina/histidina/glutamina), ARH (alanina/arginina/ histidina) e ARR (alanina/arginina/arginina) (BELT et al., 1995; HUNTER et al., 1996; DAWSON et al., 1998). O alelo ARQ é considerado a forma alélica ancestral, porque a maioria das variações do gene PRNP poderia ter derivado de uma única mutação de ponto na sequência ARQ (EFSA, 2006).

Inúmeros trabalhos indicam que a susceptibilidade aos agentes causadores do scrapie clássico é extremamente baixa em ovinos com o genótipo ARR/ARR (HUNTER et al., 1997a; ELSEN et al., 1999; THORGEIRSDOTTIR et al., 1999; ACÍN et al., 2004; BILLINIS et al., 2004). Porém, atualmente, considera-se que resistência deste genótipo às EET não é absoluta, visto que: 1) há casos confirmados de scrapie clássico em animais ARR/ARR (GROSCHUP et al., 2007); 2) há identificação em animais ARR/ARR de acúmulo atípico de PrP anormal (scrapie atípico) em ovinos (BUSCHMANN et al., 2004; LeDUR et al., 2005); 3) é comprovada a transmissão a ovinos ARR/ARR da Encefalopatia Espongiforme Bovina (EEB) após desafio intracerebral (HOUSTON et al., 2003) e desafio oral (ANDRÉOLETTI et al., 2006). Por outro lado, o alelo VRQ é considerado como associado à alta susceptibilidade às EET em ovinos (ELSEN et al., 1999; THORGEIRSDOTTIR et al., 1999; ACÍN et al., 2004; BILLINIS et al., 2004). Porém, para a EEB, uma baixa susceptibilidade dos portadores de alelo VRQ pode ser observada (FOSTER et al., 2001).

A combinação dos demais alelos apresenta resistência/susceptibilidade intermediárias e variáveis. Dawson et al. (1998) foram os primeiros a propor uma classificação para as diferentes combinações alélicas, agrupando os genótipos em 5 grupos, sendo o R 1 o mais resistente e o R5 o mais susceptível (Tabela 2).

TABELA 2: Classificação dos diferentes genótipos encontrados em ovinos, em raças onde os 5 alelos estão presentes, quanto à resistência/ susceptibilidade à scrapie

\begin{tabular}{cc}
\hline Grupo & Genótipos do PrP \\
\hline R1 & ARR/ARR \\
R2 & AHQ/AHQ; ARR/AHQ \\
R3 & ARQ/AHQ; AHQ/ARH, ARR/ARH; ARR/ARQ \\
R4 & AHQ/VRQ; ARR/VRQ; ARQ/ARQ; ARQ/ARH; \\
R5 & ARH/ARH \\
\hline
\end{tabular}

Fonte: Dawson et al. (1998). Obs.: Grupo R1 indica a menor susceptibilidade à scrapie, que vai aumentando até chegar ao grupo 5 , que tem a maior susceptibilidade.

Há muitas diferenças entre as raças de ovinos, havendo raças como a Suffolk, que apresenta essencialmente três genótipos (ARQ/ARQ, ARQ/ARR e ARR/ARR) e raças como a Texel, com os 15 genótipos normalmente encontrados em ovinos, incluindo VRQ/ VRQ (DAWSON et al., 1998). No caso da raça Suffolk, por exemplo, onde o genótipo VRQ/VRQ não é comumente encontrado, considera-se o genótipo ARQ/ ARQ como o mais susceptível para a raça (HUNTER, 2003).

Podem ocorrer outros polimorfismos de nucleotídeos únicos em outros códons como: M112T (metionina/ treonina), M137T (metionina/treonina), S138N (serina/ aspargina), L141F (leucina/fenilalanina), H143R 
(histidina/arginina), R151C (arginina/cisteína), Q171K (glutamina/lisina), N176K (aspargina/lisina) e R211Q (arginina/glutamina) (ACÍN et al., 2004). Mais de 26 polimorfismos foram confirmados por pesquisadores e outros ainda não foram caracterizados (GOLDMANN et al., 1990; 1991; LAPLANCHE et al., 1993; BELT et al., 1995; BOSSERS et al., 1996; THORGEIRSDOTTIR et al., 1999; O'ROURKE et al., 1996; DeSILVA et al., 2003; GUO et al., 2003; BILLINIS et al., 2004; HEATON et al., 2010; ANDRADE et al., 2011). A importância relativa destes polimorfismos sobre a resistência ou susceptibilidade ao scrapie ainda está por ser definida.

Além da influência do genótipo PRNP na resistência ou susceptibilidade ao agente variar entre rebanhos e raças de ovinos (DAWSON et al., 1998), a cepa presente no rebanho também será determinante (GOLDMAN et al., 1994; DAWSON et al., 1998; VACCARI et al., 2009). Por exemplo, o alelo ARQ é considerado altamente susceptível às EET em geral (inclusive à infecção experimental por EEB); porém, em um isolado em particular, tipo SSBP-1, não se consegue propagálo em animais ARQ/ARQ (GOLDMANN et al., 1994). De acordo com Baylis et al. (2004) e O'Doherty et al. (2002), ao analisar o risco de determinado genótipo estar associado ao scrapie, foram encontrados valores bastante diferentes para a presença dos alelos AHQ e ARQ.

Há inúmeras publicações sobre genotipagens em ovinos e em diversos países, especialmente europeus, cujo objetivo é conhecer a variabilidade do gene PRNP presente em seus rebanhos, a fim de servir como base para programas de seleção de animais, através de melhoramento genético. Rebanhos foram genotipados na Alemanha (JUNGHANS et al., 1998; KUTZER et al., 2002), Austrália (BOSSERS et al., 1999), Áustria (SIPOS et al., 2002), China (LAN et al., 2006; XU et al., 2011), Espanha (HURTADO et al., 2002; ACÍN et al., 2004), Estados Unidos (O'ROURKE et al., 1996; DeSILVA et al., 2003), França (ELSEN et al., 1999), Grã-Bretanha (HUNTER et al., 1997a; 1997b; TONGUE et al., 2004; EGLIN et al., 2005), Grécia (BILLINIS et al., 2004), Holanda (BELT et al., 1995), Irlanda (O'DOHERTY et al., 2000; 2001), Islândia (THORGEIRSDOTTIR et al., 1999), Itália (VACCARI et al., 2001; 2009), Nova Zelândia (BOSSERS et al., 1999), Paquistão (HUSSAIN et al., 2011), Portugal (GAMA et al., 2006), Turquia (ÜN et al., 2008; ALVAREZ et al., 2011) e União Europeia (LÜHKEN et al., 2008).

No Brasil, ainda são poucos os trabalhos de genotipagem das raças criadas no país (PASSOS et al., 2008; SOTOMAIOR et al., 2008; ANDRADE et al., 2011) e, principalmente, das raças nativas (LIMA et al., 2007; PACHECO et al., 2007). Ianella et al. (2012), no estudo com maior número de genotipagens feitas no país até o momento, analisaram 1400 animais de 13 raças, incluindo várias raças brasileiras como Bergamácia, Crioula, Morada Nova, Rabo Largo, Santa Inês e Somalis Brasileiro. Comum a todos estes trabalhos é a presença de genótipos susceptíveis ao scrapie em praticamente todas as raças estudadas.

Como é conhecido que há diferenças de susceptibilidade entre raças, rebanhos e a cepa do agente infeccioso (ACÍN et al., 2004; LÜHKEN et al., 2004; VACCARI et al., 2009), fica claro que os critérios para a seleção não necessariamente podem e devem ser aplicados igualmente para ovinos de diferentes raças, rebanhos ou países. Ainda, segundo Bishop (2006), se a doença não está presente, não se pode dizer se um animal é resistente ou não. Faz-se fundamental, portanto, estudar a relação genótipo e resistência/susceptibilidade das raças estrangeiras criadas no Brasil, das raças brasileiras e dos animais mestiços. Sotomaior (2007) relata um rebanho de ovinos Hampshire Down e também mestiços onde foi possível se avaliar a genotipagem e a presença de imunomarcação para a $\mathrm{PrPs}^{\mathrm{Sc}}$, após o abate de todos os animais. No grupo dos animais mestiços, encontrou-se uma relação entre o genótipo ARR/ARQ e uma maior susceptibilidade, diferente de alguns dados da literatura (VAN KEULEN et al., 1996; ANDRÉOLETTI et al., 2000). Isto reforça a necessidade de avaliarem-se mais rebanhos com a presença de scrapie no Brasil. OrtizPelaez e Bianchini (2011) demonstram a importância de se estudar rebanhos afetados pela doença, analisando fatores genéticos, ambientais e de manejo. A avaliação de genótipos em rebanhos afetados permite a determinação do risco, utilizando a completa genotipagem do grupo e a frequência da doença, mensurada pela prevalência, quando os animais são sacrificados em programas de controle. 
Portanto, em países onde há presença do agente infeccioso, é possível estudar a associação dos genótipos, nas diferentes raças, com a presença da doença; além de direcionar os cruzamentos, principalmente se existirem programas de controle de scrapie no país. Mesmo nos países onde a doença não está relatada, a genotipagem permite uma visualização do grau de susceptibilidade que aqueles rebanhos, ou raças, teriam caso o agente estivesse presente. Dessa forma, é possível dimensionar a possibilidade de inclusão desta característica em futuros programas de seleção, que visem aumentar a resistência à doença, porém, sem perder ou prejudicar outras características produtivas (SOTOMAIOR et al., 2008).

\section{Programas de controle}

Em uma revisão sobre scrapie, Dawson et al. (2008) reforçam o fato de que, historicamente, esta doença é considerada de difícil controle. Aspectos ainda não totalmente elucidados da etiologia, patogenia e epidemiologia, somados ao fato de não existir nenhum tratamento possível, nem a possibilidade de vacinação, visto que a infecção não induz resposta humoral, tornam o controle do scrapie um grande desafio.
Desde a primeira publicação (HUNTER et al., 1989) indicando que variações no gene PRNP poderiam estar relacionadas à resistência ou susceptibilidade dos ovinos a scrapie, dezenas de milhares de animais foram genotipados. Somente o National Scrapie Plan (NSP) da Grã-Bretanha genotipou mais de um milhão de ovinos (HUNTER, 2006).

Na Grã-Bretanha, o serviço de genotipagem comercial dos rebanhos ovinos está disponível desde 1994. Segundo Melchior et al. (2010), a preocupação com o controle da doença começou com fazendeiros ingleses que iniciaram a genotipagem dos seus rebanhos para melhorar o comércio de matrizes e reprodutores e proporcionar uma maior segurança ao produtor quanto aos riscos do animal desenvolver a doença. Em 2001, foi lançado o National Scrapie Plan (NSP) (disponível em http://www.defra.gov.uk) para rebanhos de raças puras registradas, posteriormente estendido para os rebanhos de raças puras não registradas em 2002 (RODEN et al., 2006). O programa, de adesão voluntária, atualmente utiliza o sistema de dados denominado RAM Genotyping Scheme (RGS), onde há seleção positiva do alelo ARR e seleção negativa do alelo VRQ, além de definir cruzamentos restritos de acordo com cada genótipo (Tabela 3). Outros países da Europa também tiveram a

TABELA 3: Classificação dos diferentes genótipos encontrados em ovinos quanto ao grau de resistência/susceptibilidade ao scrapie, segundo o Ram Genotyping Scheme do NSP.

\begin{tabular}{ccc}
\hline Tipo & Genótipos & Grau de resistência/susceptibilidade \\
\hline 1 & ARR/ARR & Ovinos que são geneticamente mais resistentes ao scrapie \\
& ARR/AHQ & Ovinos que são geneticamente resistentes ao scrapie, mas que necessitam de seleção cuidadosa quando \\
& ARR/ARH & utilizados para cruzamentos \\
& ARR/ARQ & \\
& AHQ/AHQ & \\
& AHQ/ARH & \\
3 & AHQ/ARQ & Ovinos que geneticamente têm pouca resistência ao scrapie e que necessitam de seleção cuidadosa quando \\
& ARH/ARH & utilizados para cruzamentos \\
& ARH/ARQ & \\
& ARQ/ARQ & \\
4 & ARR/VRQ & Ovinos que são geneticamente susceptíveis ao scrapie e que não devem ser utilizados para reprodução, exceto \\
& AHQ/VRQ & dentro de um programa controlado de reprodução aprovado pelo National Scrapie Plan Administration Centre \\
& ARH/VRQ & Ovinos que são geneticamente muito susceptíveis ao scrapie e que não devem ser utilizados para reprodução \\
& ARQ/VRQ & \\
\hline & VRQ/VRQ & \\
\hline
\end{tabular}

Fonte: adaptado do NSP Genotypes Table - DEFRA.

Disponível em: <http://www.defra.gov.uk/animalh/bse/othertses/scrapie/nsp/publicatsrpts/tables.htm)>. 
mesma preocupação com os seus rebanhos e iniciaram alguns programas de controle, como foi o caso da Alemanha (DAWSON et al., 2008).

Nos Estados Unidos, o Serviço de Inspeção Sanitária Animal e Vegetal (Animal Plant Health Inspection Service - APHIS) do Departamento de Agricultura (USDA) usa a genotipagem para determinar quais os animais que, após terem sido expostos à infecção pelo agente da forma clássica de scrapie, devem ser removidos ou restrito aos rebanhos afetados e quais estão livres para deslocamentos de forma irrestrita. São reconhecidos como importantes os códons 171 e 136 na determinação da susceptibilidade a scrapie nos EUA. O plano americano, denominado The National Genetics Based Flock Clean-up Plan permite que criadores com rebanhos afetados permaneçam ou desloquem ovinos classificados como $\mathrm{RR}_{171} ; \mathrm{AA}_{136} \mathrm{QR}_{171}$ e a maioria dos $\mathrm{AV}_{136} \mathrm{QR}_{171}$ de forma irrestrita. Também há que se remover ou restringir todas as ovelhas QQ expostas, cabras expostas e os descendentes de ovelhas acometidas por scrapie (APHIS, 2005).

Os planos e programas de controle a scrapie objetivam simultaneamente o aumento da frequência do alelo ARR e a diminuição do alelo VRQ (DAWSON et al., 2008). Entretanto, com a ocorrência dos casos atípicos de scrapie (BENESTAD et al., 2003) com diferentes padrões de relação com o genótipo do gene PRNP, estas estratégias dos planos de controle tem sido questionadas. Os casos atípicos tem sido correlacionados com os alelos AF141RQ e AHQ (MOUM et al., 2005; BENESTAD et al., 2008), enquanto que animais considerados resistentes são portadores do alelo VRQ.

Outras preocupações, como diminuição da variabilidade genética, também tem sido levantadas pela comunidade científica (BISHOP, 2006; EFSA, 2006; ROUGHSEDGE et al., 2006). Apesar destas preocupações, uma avaliação de risco biológico considerou que, baseado nos dados disponíveis, não existem riscos associados com os atuais programas de cruzamentos da União Europeia (EFSA, 2006).

Segundo Dawson et al. (2008), o NSP tem sido um sucesso em seus objetivos e, em conjunto com outros programas similares em países europeus, demonstra que a seleção baseada no genótipo do gene PRNP é possível. Ortiz-Pelaez e Bianchini (2011), analisando quase 320.000 animais genotipados no NSP da Grã-Bretanha para avaliar o impacto do genótipo na prevalência do scrapie clássico na população, concluíram que um aumento da proporção de genótipos ARR/ARR correspondeu a uma diminuição dos casos clínicos de scrapie. Os genótipos ARR/AHQ, AHQ/VRQ, ARH/ VRQ e ARQ/VRQ, classificados como tipo 5 pelo NSP (Tabela 3), e os alelos ARH, ARQ, AHQ e VRQ estão associados a um aumento no número de casos da doença.

No Brasil, não existe nenhum programa de controle baseado na seleção de genótipos resistentes ao scrapie. Alguns trabalhos mostram que existem diferenças nas frequências genotípicas do gene PRNP, quando comparados aos resultados de outros países (SOTOMAIOR, 2007), indicando a necessidade de se ampliar o número de animais genotipados antes que qualquer programa de controle do scrapie seja implantado no Brasil. É essencial, também, que se conheça a estrutura populacional e o grau de variabilidade genética do gene PRNP entre as diferentes raças, como tem sido demonstrado nos primeiros trabalhos brasileiros sobre genotipagem de ovinos (LIMA et al., 2007; PACHECO et al., 2007; PASSOS et al., 2008; SOTOMAIOR et al. 2008; ANDRADE et al., 2011; IANELLA et al., 2012).

Num mundo globalizado, observa-se o aumento de barreiras sanitárias, em substituição às alfandegárias. A presença de scrapie no Brasil e o perfil de genótipos susceptíveis nas principais raças criadas no país pode ser uma dificuldade para a exportação destes animais e seus produtos, inclusive de outras espécies como bovinos e suínos. Portanto, programas de controle e vigilância de doenças devem ser conduzidos com muito cuidado e responsabilidade, para garantir a aceitação dos produtos brasileiros sem quaisquer restrições. Vale ressaltar, também, que qualquer programa de seleção deve ser conduzido de forma gradual, combinando a manutenção de variabilidade genética, adaptação e produção com a resistência a doenças (SOTOMAIOR et al., 2008).

A possibilidade de implementação de programas de seleção genética de animais resistentes a scrapie deve ser considerada como uma importante ferramenta para impedir a disseminação da doença em rebanhos 
de ovinos e caprinos nas diferentes regiões do Brasil e garantir a qualidade sanitária destes animais, além de fortalecer a posição comercial do Brasil em negociações no mercado agropecuário internacional.

\section{Referências}

ACÍN, C.; MARTÍN-BURRIEL, I.; GOLDMANN, W.; LYAHYAI, J.; MONZÓN, M.; BOLEA, R.; SMITH, A.; RODELLAR, C.; BADIOLA, J. J.; ZARAGOZA, P. Prion protein gene polymorphisms in healthy and scrapie-affected Spanish sheep. Journal of General Virology, London, v. 85, p. 2103-2110, 2004.

ALVAREZ, A. L.; GUTIERREZ-GILA, B.; UZUNB, M.; PRIMITIVO, F. S.; ARRANZA, J. J. Genetic variability in the príon protein gene in five indigenous Turkish sheep breeds. Small Ruminant Research, Amsterdam, v. 99, p. 93-98, 2011.

APHIS. Animal disease eradication programs and control and certification programs. 2005. Disponível em: <http://www.aphis. usda.gov/publications/animal_health/content/printable_version/ AHR_Web_PDF/E_chapter_3.pdf $>$. Acesso em: 18 ago. 2011.

ANDRADE, C. P.; ALMEIDA, L. L.; CASTRO, L. A.; LEAL, J. S.; SILVA, S. C.; DRIEMEIER, D. Single nucleotide polymorphisms at 15 codons of the prion protein gene from a scrapie-affected herd of Suffolk sheep in Brazil. Pesquisa Veterinária Brasileira, Rio de Janeiro, v. 31, n. 10, p. 893-898, 2011.

ANDRÉOLETTI, O.; BERTHON, P.; MARC, D.; SARRADIN, P.; GROSCLAUDE, J.; KEULEN, L. VAN; SCHELCHER, F.; ELSEN, J. M.; LANTIER, F. Early accumulation of $\mathrm{PrP}^{\mathrm{Sc}}$ in gutassociated lymphoid and nervous tissues of susceptible sheep from a Romanov flock with natural scrapie. Journal of General Virology, London, v. 81, p. 3115-3126, 2000.

ANDRÉOLETTI, O.; MOREL, N.; LACROUX, C.; ROUILLON, V.; BARC, C.; TABOURET, G.; SARRADIN, P.; BERTHON, P.; BERNARDET, P.; MATHEY, J.; LUGAN, S.; COSTES, P.; CORBIERE, F.; ESPINOSA, J. C.; TORRES, J. M.; GRASSI, J.; SCHELCHER, F.; LANTIER, F. Bovine spongiform encephalopathy agent in spleen from an ARR/ ARR orally exposed sheep. Journal of General Virology, London, v. 87, n. 4, p. 10431046, 2006.

BAYLIS, M.; CHIHOTA, C.; STEVENSON, E.; GOLDMANN, W.; SMITH, A.; SIVAM, K.; TONGUE, S.; GRAVENOR, M. B. Risk of scrapie in British sheep of different prion protein genotype. Journal of General Virology, London, v. 85, p. 2735-2740, 2004. BELT, P. B. G. M.; MUILEMAN, I. H.; SCHREUDER, B. E. C.; BOS-DE-RUIJTER, J.; GIELKENS, A. L. J.; SMITS, M. A. Identification of five allelic variants of the sheep PrP gene and their association with natural scrapie. Journal of General Virology, London, v. 76, p. 509-517, 1995.

BENESTAD, S. L.; ARSAC, J. N.; GOLDMANN, M. N. Atypical/ Nor98 scrapie: properties of the agent, genetics, and epidemiology. Veterinary Research, Paris, v. 39, p. 19, 2008.

BENESTAD, S. L.; SARRADIN, P.; THU, B.; SCHÖNHEIT, J.; TRANULIS, M. A.; BRATBERG, B. Cases of scrapie with unusual features in Norway and designation of a new type, Nor98. Veterinary Record, London, v. 153, p. 202-208, 2003.
BILLINIS, C.; PSYCHAS, V.; LEONTIDES, L., SPYROU, V.; ARGYROUDIS, S.; VLEMMAS; I.; LEONTIDES, S.; SKLAVIADIS, T.; PAPADOPOULOS, O. Prion protein gene polymorphisms in healthy and scrapie-affected sheep in Greece. Journal of General Virology, London, v. 85, p. 547-554, 2004.

BISHOP, S. The potential adverse consequences of breeding for resistance. In: INTERNATIONAL CONFERENCE - PRION DISEASES OF DOMESTIC LIVESTOCK, 2006, London. Abstracts... London: Veterinary Laboratory Agency, 2006, p. 28.

BISHOP, S. C.; MORRIS, C. A. Genetics of disease resistance in sheep and goats. Small Ruminant Research, Amsterdam, v. 70, p. 48-59, 2007.

BOSSERS, A.; HARDERS, F. L.; SMITS, M. A. PrP genotype frequencies of the most dominant sheep breed in a country free from scrapie. Archives of Virology, Wien, v. 144, p. 829-834, 1999.

BOSSERS, A.; SCHREUDER, B. E.; MUILEMAN, I. H.; BELT, P. B.; SMITS, M. A. PrP genotype contributes to determining survival times of sheep with natural scrapie. Journal of General Virology, London, v. 77, v. 10, p. 2669-2673, 1996.

BRASIL. Ministério da Agricultura, Pecuária e Abastecimento. Instrução Normativa $\mathbf{N}^{\mathbf{0}} \mathbf{1 5}$, de 02 de abril de 2008. Brasília: Diário Oficial da União, 2008.

BUSCHMANN, A.; LÜHKEN, G.; SCHULTZ, J.; ERHARDT, G.; GROSCHUP, M. H. Neuronal accumulation of abnormal prion protein in sheep carrying a scrapie resistant genotype (PrP ARR/ ARR). Journal of General Virology, London, v. 85, p. 2727-2733, 2004.

CAUGHEY, B. W.; DONG, A.; BHAT, K. S.; ERNST, D.; HAYES, S. F.; CAUGHEY, W. S. Secondary structure analysis of the scrapieassociated protein PrP 27-30 in water by infrared spectroscopy. Biochemistry, Washington, v. 30, v. 43, p. 7672-7680, 1991.

DAWSON, M.; HOINVILLE, L. J.; HOSIE, B. D.; HUNTER, N. Guidance on the use of PrP genotyping as an aid to the control of clinical scrapie. Veterinary Record, London, v. 142, p. 623-625, 1998.

DAWSON, M.; MOORE, R. C.; BISHOP, S. C. Progress and limits of PrP gene selection. Veterinary Research, Paris, v. 39, n. 25, s/ paginação, 2008.

DETWILER, L. A.; BAYLIS, M. The epidemiology of scrapie. Revue Scientifique et Technique. Office International des Epizooties, Paris, v. 22, n. 1, p. 121-143, 2003.

DEFRA. National scrapie plan for Great Britain. Department for Food, Environment and Rural Affairs, 2003. Disponível em: $<$ http://archive.defra.gov.uk/foodfarm/farmanimal/diseases/atoz/ bse/othertses/scrapie/nsp.htm>. Acesso em: 10 ago. 2011.

DeSILVA, U.; GUO, X.; KUPFER, D. M.; FERNANDO, S. C.; PILLAI, A. T. V.; NAJAR, F. Z.; SO, S.; FITCH, G. Q.; ROE, B. A. Allelic variants of ovine prion protein gene(PRNP) in Oklahoma sheep. Cytogenetic and Genome Research, Basel, v. 102, p. 8994, 2003.

EFSA. Opinion of the Scientific Panel on Biological Hazards on the breeding programme for TSE resistance in sheep. The EFSA Journal, London, v. 382, p. 1-46, 2006.

EGLIN, R. D.; WARNER, R.; GUBBINS, S.; SIVAM, S. K.; DAWSON, M. Frequencies of PrP genotypes in 38 breeds of sheep sampled in the National Scrapie Plan for Great Britain. Veterinary Record, London, v. 156, p. 433-437, 2005. 
ELSEN, J. M.; AMIGUES, Y.; SCHELCHER, F.; DUCROCQ, V.; ANDREOLETTI, O.; EYCHENNEM, F.; TIEN KHANG, J. V.; POIVEY, J. P.; LANTIER, F.; LAPLANCHE, J. L. Genetic susceptibility and transmission factors in scrapie: detailed analysis of an epidemic in a closed flock of Romanov. Archives of Virology, Wien, v. 144, p. 431-445, 1999.

FERNANDES, R. E.; REAL, C. M.; FERNANDES, J. C. T. "Scrapie" em ovinos no Rio Grande do Sul. Arquivos da Faculdade de Veterinária da UFRGS, Porto Alegre, v. 6, p. 139-143, 1978.

FOSTER, J. D.; PARNHAM, D.; CHONG, A.; GOLDMANN, W.; HUNTER, N. Clinical signs, histopathology and genetics of experimental transmission of BSE and natural scrapie to sheep and goats. Veterinary Record, London, v. 148, n. 6, p. 165-171, 2001.

GAMA, L. T.; CAROLINO, M. I.; SANTOS-SILVA, M. F.; PIMENTA, J. A.; COSTA, M. S. Prion protein genetic polymorphisms and breeding strategies in Portuguese breeds of sheep. Livestock Science, Amsterdam, v. 99, p. 175-184, 2006.

GOLDMANN, W.; HUNTER, N.; FOSTER, J. D.; SALBAUM, J. M.; BEUREYTHER, K.; HOPE, J. Two alleles of a neural protein gene linked to scrapie in sheep. Proceedings of the National Academy of Sciences of the United States of America, Washington, v. 87, p. 2476-2480, 1990.

GOLDMANN, W.; HUNTER, N.; MARTIN, T.; DAWSON, M.; HOPE, J. Different forms of the bovine PrP gene have five or six copies of a short, G-C-rich element within the protein-coding exon. Journal of General Virology, London, v. 72, n. 1, p. 201-204, 1991.

GOLDMANN, W.; HUNTER, N.; SMITH, G.; FOSTER, U.; HOPE, J. PrP genotype and agent effects in scrapie: change in allelic interaction with different isolates of agent in sheep, a natural host of scrapie. Journal of General Virology, London, v. 75, n. 5, p. 989-995, 1994.

GONZÁLEZ, L.; DAGLEISH, M. P.; BELLWORTHY, S. J.; SISÓ, S.; STACK, M. J.; CHAPLIN, M. J.; DAVIS, L. A.; HAWKINS, S. A.; HUGHES, J.; JEFFREY, M. Postmortem diagnosis of preclinical and clinical scrapie in sheep by detection of diseaseassociated PrP in their rectal mucosa. Veterinary Record, London, v. 158, p. $325-331,2006$.

GONZÁLEZ L.; DAGLEISH, M. P.; MARTIN, S.; DEXTER G.; STEELE P.; FINLAYSON J.; JEFFREY M. Diagnosis of preclinical scrapie in live sheep by immunohistochemical examination of rectal biopsies. Veterinary Record, London, v. 162, p. 397-403, 2008a.

GONZÁLEZ, L.; HORTON, R.; RAMSAY, D.; TOOMIK, R.; LEATHERS, V.; TONELLI, Q.; DAGLEISH, M. P.; JEFFREY, M.; TERRY, L. Adaptation and evaluation of a rapid test for the diagnosis of sheep scrapie in samples of rectal mucosa. Journal of Veterinary Diagnostic Investigation, Thousand Oaks, v. 20, p. 203-208, 2008b.

GONZÁLEZ, L.; JEFFREY, M.; SISÓ, S.; MARTIN, S.; BELLWORTHY, S. J.; STACK, M. J.; CHAPLIN, M. J.; DAVIS, L.; DAGLEISH, M.; REID, H. Diagnosis of preclinical scrapie in samples of rectal mucosa. Veterinary Pathology, Basel, v.156, p. 846-847, 2005.

GROSCHUP, M. H.; LACROUX, C.; BUSCHMANN, A.; LÜHKEN, G.; MATHEY, J.; EIDEN, M.; LUGAN, S.; HOFFMANN, C.; ESPINOSA, J. C.; BARON, T.; TORRES, J. M.; ERHARDT, G.; ANDREOLETTI, O. Classic scrapie in sheep with the ARR/ARR prion genotype in Germany and France. Emerging Infectious Diseases, Atlanta, v. 13, p. 1201-1207, 2007.

GUO, X.; KUPFER, D. M.; FITCH, G. Q.; ROE, B. A.; DeSILVA, $\mathrm{U}$. Identification of a novel lysine-171 allele in the ovine prion protein (PRNP) gene. Animal Genetics, Oxford, v. 34, n. 4, p. $303-$ 305, 2003.

HARRIS, D. A. Cellular biology of prion disease. Clinical Microbiology Reviews, Washington, v. 12, p. 429-444, 1999.

HEATON, M. P.; LEYMASTER, K. A.; KALBFLEISCH, T. S.; FREKING, B. A.; SMITH, T. P. L.; CLAWSON, M. L.; LAEGREID, W. W. Ovine reference materials and assays for prion genetic testing. BMC Veterinary Research, London, v. 6, n. 23, s/ paginação, 2010.

HOINVILLE, L. J. A review of the epidemiology of scrapie in sheep. Revue Scientifique et Technique de l'Office International des Epizooties, Paris, v. 15, p. 827-852, 1996.

HOUSTON, F.; GOLDMANN, W.; CHONG, A.; JEFFREY, M.; GONZÁlEZ, L.; FOSTER, J.; PARNHAM, D.; HUNTER, N. Prion diseases: BSE in sheep bred for resistance to infection. Nature, London, v. 423, p. 498, 2003.

HUNTER, N. PrP genetics in sheep and the implications for scrapie and BSE. Trends in Microbiology, Cambridge, v. 5, n. 8, p. 331334, 1997.

HUNTER, N. Scrapie and experimental BSE in sheep. British Medical Bulletin, London, v. 66, p. 171-183, 2003.

HUNTER, N. The role of genetics in the epidemiology and pathogenesis of scrapie. In: INTERNATIONAL CONFERENCE PRION DISEASES OF DOMESTIC LIVESTOCK, 2006, London. Abstracts...London: Veterinary Laboratory Agency, 2006, p. 26.

HUNTER, N.; FOSTER, J. D.; DICKINSON, A. G.; HOPE, J. Linkage of the gene for scrapie-associated fibril protein (PrP) to the Sip gene in Cheviot sheep. Veterinary Record, London, v. 124, p. 364-366, 1989.

HUNTER, N.; FOSTER, J. D.; GOLDMANN, W.; STEAR, M. J.; BOSTOCK, C. Natural scrapie in a closed flock of Cheviot sheep occurs only in specific PrP genotypes. Archives of Virology, Wien, v. 141, p. 809-824, 1996.

HUNTER, N.; GOLDMANN, W.; FOSTER, J. D.; CAIRNS, D.; SMITH, G. Natural scrapie and PrP genotype: case-control studies in British sheep. Veterinary Record, London, v. 141, p. 137-140, $1997 \mathrm{a}$.

HUNTER, N.; MOORE, L.; HOSIE, B. D.; DINGWALL, W. S.; GREIG, A. Association between natural scrapie and PrP genotype in a flock of Suffolk sheep in Scotland. Veterinary Record, London, v. 140, p. 59-63, 1997 b.

HURTADO,A.; GARCÍA-PÉREZ, A. L.; BELTRÁN de HEREDIA, I.; BARANDIKA, J.; SANZ-PARRA, A.; BERRIATUA, E.; JUSTE, R. A. Genetic susceptibility to scrapie in a population of Latxa breed in the Basque Country, Spain. Small Ruminant Research, Amsterdam, v. 45, p. 255-259, 2002.

HUSSAIN, A.; BABAR, M. E.; IMRAN, M.; HAQ. I. U.; JAVED, M. M. Detection of four novel polymorphisms in PrP gene of Pakistani sheep (Damani and Hashtnagri) and goats (Kamori and Local Hairy) breeds. Virology Journal, London, v. 8, n. 246, 2011. IANELLA, P.; McMANUS, C. M.; CAETANO, A. R.; PAIVA, S. R. PRNP haplotype and genotype frequencies in Brazilian sheep: 
Issues for conservation and breeding programs. Research in Veterinary Science, London, v. 93, n. 1, p. 219-225, 2012.

JEFFREY, M.; MARTIN, S.; THOMSON, J. R.; DINGWALL, W. S.; BEGARA-MCGORUM, I.; GONZÁLEZ, L. Onset and distribution of tissue PrP accumulation in scrapie-affected Suffolk sheep as demonstrated by sequential necropsies and tonsillar biopsies. Journal of Comparative Pathology, London, v. 125, p. 48-57, 2001.

JUNGHANS, F.; TEUFEL, B.; BUSCHMANN, A.; STENG, G.; GROSCHUP, M. H. Genotyping of German sheep with respect to scrapie susceptibility. Veterinary Record, London, v. 143, p. 340341, 1998.

KUTZER, T.; PFEIFFER, I.; BRENIG, B. Identification of new allelic variants in the ovine prion protein $(\mathrm{PrP})$ gene. Journal of Animal Breeding and Genetics, Berlin, v. 119, p. 201-208, 2002.

LAN, Z.; WANG, Z. L.; LIU, Y.; ZHANG, X. Prion protein gene (PRNP) polymorphisms in Xinjiang local sheep breeds in China. Archives of Virology, Wien, v. 151, p. 2095-2101, 2006.

LAPLANCHE, J.L.; CHATELAIN, J.; BEAUDRY,P.; DUSSAUCY, M.; BOUNNEAU, C.; LAUNAY, J. M. French autochthonous scrapied sheep without the 136Val PrP polymorphism. Mammalian Genome, New York, v. 4, n. 8, p. 463-464, 1993.

LeDUR, A.; BERINGUE, V.; ANDREOLETTI, O.; REINE, F.; LAI, T. L.; BARON, T.; BRATBERG, B.; VILOTTE, J. L.; SARRADIN, P.; BENESTAD, S. L.; LAUDE, H. A newly identified type of scrapie agent can naturally infect sheep with resistant $\operatorname{PrP}$ genotypes. Proceedings of the National Academy of Sciences of the United States of America, Washington, v. 102, n. 44. p. 1603116036, 2005.

LEE, I. Y.; WESTAWAY, D.; SMIT, A. F. A.; WANG, K.; SETO, J., CHEN, L.; ACHARYA, C.; ANKENER, M.; BASKIN, D.; COOPER, C.; YAO, H.; PRUSINER, S. B.; HOOD, L. E. Complete genomic sequence and analysis of the prion protein gene region from three mammalian species. Genome Research, Cold Spring Harbor, v. 8, p. 1022-1037, 1998.

LIMA, A. C. B.; BOSSERS, C. E.; SOUZA, S. M. P.; OLIVEIRA, S. M.; OLIVEIRA, D. M. PrP genotypes in a pedigree flock of a Santa Inês sheep. Veterinary Record, London, v. 160, p. 336-337, 2007.

LÜHKEN, G.; BUSCHMANN, A.; GROSCHUP, M. H.; ERHARDT, G. Prion protein allele $\mathrm{A}_{136} \mathrm{H}_{154} \mathrm{Q}_{171}$ is associated with high susceptibility to scrapie in purebred and crossbred German Merinoland sheep. Archives of Virology, Wien, v. 149, n. 8, p. 1571-1580, 2004.

LÜHKEN, G.; LIPSKY, S.; PETER, C.; ERHARDT, G. Prion protein polymorphisms in autochthonous European sheep breeds in respect to scrapie eradication in affected flocks. Small Ruminant Research, Amsterdam, v. 75, p. 43-47, 2008.

MASTRANGELO, P.; WESTAWAY, D. Biology of the prion gene complex. Biochemistry and Cell Biology, Ottawa, v. 79, p. 613$628,2001$.

MELCHIOR, M. B.; WINDIG, J. J.; HAGENAARS, T. J.; BOSSERS, A.; DAVIDSE, A.; VAN ZIJDERVELD, F. G: Eradication of scrapie with selection breeding: are we nearly there? BMC Veterinary Research, London, v. 6, n. 24, s/paginação, 2010. MOUM, T.; OLSAKER, I.; HOPP, P.; MOLDAL, T.; VALHEIM, M.; MOUM, T.; BENESTAD, S. L. Polymorphisms at codons 141 and 154 in the ovine prion protein gene are associated with scrapie Nor98 cases. Journal of General Virology, London, v. 86, p. 231235, 2005.

OIE. Terrestrial manual. 2009. Disponível em: <http://www. oie.int/eng/Normes/mmanual/2008/pdf/2.07.13_SCRAPIE.pdf $>$. Acesso em: 4 maio 2010.

OJEDA, D. B.; OLIVEIRA, N. M. Serviço de Avaliação Genética de Reprodutores Ovinos. S.A.G.R.O.: Resultados de 1998. Bagé: Embrapa Pecuária Sul, 1998. 31 p.

OLLHOFF, R. D.; SOTOMAIOR, C. S. Scrapie. Boletim Técnico. Instituto Biológico, São Paulo, v. 24, p. 54-60, 2011.

O'DOHERTY, E.; AHERNE, M.; ENNIS, S.; WEAVERS, E.; HUNTER, N.; ROCHE, J. F.; SWEENEY, T. Detection of polymorphisms in the prion protein gene in a population of Irish Suffolk sheep. Veterinary Record, London, v. 146, p. 335-338, 2000.

O'DOHERTY, E.; AHERNE, M.; ENNIS, S.; WEAVERS, E.; ROCHE, J. F.; SWEENEY, T. Prion protein gene polymorphisms in pedigree sheep in Ireland. Research in Veterinary Science, London, v. 70, p. 51-56, 2001.

O'DOHERTY, E.; HEALY, A.; AHERNE, M.; HANRAHAN, J. P.; WEAVERS, E.; O’DOHERTY, M.; ROCHE, J. F.; GUNN, M.; SWEENEY, T. Prion protein (PrP) gene polymorphisms associated with natural scrapie cases and their flock-mates in Ireland. Research in Veterinary Science, London,v. 73, p. 243-250, 2002.

O'ROURKE, K. I.; BASZLER, T. V.; BESSER, T. E.; MILLER, J. M.; CUTLIP, R. C.; WELLS, G. A. H.; RYDER, S. J.; PARISH, S. M.; HAMIR, A. N.; COCKETT, N. E.; JENNY, A.; KNOWLES, D. P. Preclinical diagnosis of scrapie by immunohistochemistry of third eyelid lymphoid tissue. Journal of Clinical Microbiology, Washington, v. 38, n. 9, p. 3254-3259, 2000.

O'ROURKE, K. I.; BASZLER, T. V.; PARISH, S. M.; KNOWLES, D. P. Preclinical detection of $\mathrm{PrP}^{\mathrm{Sc}}$ in nictitating membrane lymphoid tissue of sheep. Veterinary Record, London, v. 142, p. 489-491, 1998.

O'ROURKE, K. I.; MELCO, R. P.; MICKELSON, J. R. Allelic frequency of an ovine scrapie susceptibility gene. Animal Biotechnology, New York, v. 7, p. 155-162, 1996.

ORTIZ-PELAEZ, A.; BIANCHINI, J. The impact of the genotype on the prevalence of classical scrapie at population level. Veterinary Research, London, v. 42, p. 1-8, 2011.

PACHECO, A. C. L.; OLIVEIRA, S. M. P.; GOUVEIA, J. J. S.; DINIZ, M. C.; VASCONCELOS, E. J. R.; VIANA, D. A.; ROSINHA, G. M. S.; MAGGIONI, R.; COSTA, R. B.; OLIVEIRA, D. M. Analysis of prion protein gene (PRNP) polymorphisms in healthy Morada Nova sheep reveals the presence of genotypes susceptible to scrapie. Ciência Animal, Fortaleza, v. 17, p. 27-36, 2007.

PASSOS, D. T.; RIBEIRO, L. A. O.; RODRIGUES, N. C.; HEPP, D.; WEIMER, T. A. PrP polymorphisms in Brazilian sheep. Small Ruminant Research, Amsterdam, v. 74, p. 130-133, 2008.

POHL DE SOUZA, F. P.; SOTOMAIOR, C. S.; OLLHOFF, R. D.; RODRIGUES, N. Ocorrência de três casos de tremor enzoótico dos ovinos. In: CONGRESSO LATINO-AMERICANO DE ESPECIALISTAS EM PEQUENOS RUMINANTES E CAMELÍDEOS SUL-AMERICANOS, IV, 2005, Curitiba. Anais... Curitiba: AVEPER, 2005. Versão eletrônica. 
PRUSINER, S. B. Novel proteinaceus infectious particles cause scrapie. Science, Washington, v. 216, p. 136-144, 1982.

PRUSINER, S. B. Prions. Proceedings of the National Academy of Sciences of the United States of America, Washington, v. 95, p 13363-13383, Nobel Lecture, 1998.

RIBEIRO, L. A. O. Enfermidades de ruminantes diagnosticadas no CPVDF, RS. In: ENCONTRO DE LABORATÓRIOS DE DIAGNÓSTICO VETERINÁRIO DO CONE SUL, 1, 1996, Campo Grande. Anais... Campo Grande, 1996. p. 89-95.

RIBEIRO, L. A. O.; PASSOS, D. T.; RODRIGUES, N. C.; WEIMER, T. A. Scrapie (paraplexia enzoótica) em ovinos no Brasil. Veterinária em Foco, Canoas, v. 4, p. 203-209, 2007.

RIBEIRO, L. A. O.; RODRIGUES, N. C. Scrapie. A Hora Veterinária, Porto Alegre, v. 120, p. 15-22, 2001.

RODEN, J. A.; NIEUWHOF, G. J.; BISHOP, S. C.; JONES, D. A.; HARESIGN, W.; GUBBINS, S. Breeding programmes for TSE resistance in British sheep. I. Assessing the impact on prion protein (PrP) genotype frequencies. Preventive Veterinary Medicine, Amsterdam, v. 73, n. 1, p. 1-16, 2006.

ROUGHSEDGE, T.; VILLANUEVA, B.; WOOLLIAMS, J. A. Determining the relationship between restorative potential and size of a gene bank to alleviate the risks inherent in a scrapie eradication breeding programme. Livestock Science, Amsterdam, v. 100, p. 231-241, 2006.

RYDER, S.; DEXTER, G.; BELLWORTHY, S.; TONGUE, S. Demonstration of lateral transmission of scrapie between sheep kept under natural conditions using lymphoid tissue biopsy. Research in Veterinary Science, London, v. 76, p. 211-217, 2004.

SIPOS, W.; KRAUS, M.; SCHMOLL, F; ACHMANN, R.; BAUMGARTNER, W. PrP genotyping of Austrian sheep breeds. Journal of Veterinary Medicine Series A, Berlin, v. 49, n. 8, p. 415-418, 2002.

SOTOMAIOR, C. S. Polimorfismo do gene da proteína prion celular $\left(\operatorname{Pr}^{\mathrm{C}}\right)$ e a susceptibilidade/resistência ao scrapie em ovinos no estado do Paraná. 2007. 120 f. Tese (Doutorado em Processos Biotecnológicos) - Universidade Federal do Paraná, Curitiba. 2007.
SOTOMAIOR, C. S.; SOTOMAIOR, V. S.; MADEIRA, H. M. F.; THOMAZ-SOCCOL, V. Prion protein gene polymorphisms in sheep in the State of Paraná, Brazil. Animal Genetics, Oxford, v. 39, p. 659-661, 2008.

STEVENS, K. B.; DEL RÍO VILAS, V. J.; GUITIÁN, J. Classical sheep scrapie in Great Britain: spatial analysis and identification of environmental and farm-related risk factors. BMC Veterinay Research, London, v. 5, n. 33, s/paginação, 2009.

THORGEIRSDOTTIR, S.; SIGURDARSON, S.; THORISSON, H. M.; GEORGSSON, G.; PALSDOTTIR, A. PrP gene polymorphism and natural scrapie in Icelandic sheep. Journal of General Virology, London, v. 80, p. 2527-2534, 1999.

TONGUE, S. C.; WILESMITH, J. W.; COOK, C. J. Frequencies of prion protein $(\mathrm{PrP})$ genotypes and distribution of ages in 15 scrapie affected flocks in Great Britain. Veterinary Record, London, v. 154, p. 9-16, 2004.

ÜN, C.; OZTABAK, K.; OZDEMIR, N.; AKIS, I.; MENGI, A. Genotyping of PrP gene in native Turkish sheep breeds. Small Ruminant Research, Amsterdam, v.74, p.260-264, 2008.

VACCARI, G.; PETRAROLI, R.; AGRIMI,U.; ELENI, C.; PERFETTI, M. G.; DiBARI, M. A.; MORELLI, L.; LIGIOS, C.; BUSANI, L.; NONNO, R.; DiGUARDO, G. PrP genotype in Sarda breed sheep and its relevance to scrapie. Archives of Virology, Wien, v. 146, p. 2029-2037, 2001.

VACCARI, G.; SCAVIA, G.; SALA, M.; COSSEDDU, G.; CHIAPPINI, B.; CONTE, M., ESPOSITO, E.; LORENZETTI, R.; PERFETTI, G.; MARCONI, P.; SCHOLL, F.; BARBARO, K.; BELLA, A.; NONNO, R.; AGRIMI, U. Protective effect of the AT137RQ and ARQK136 PrP alleles against classical scrapie in Sarda breed sheep. Veterinary Research, Paris, v.40: 19, 2009.

VAN KEULEN, L. J.; SCHREUDER, B. E.; MELOEN, R. H.; MOOIJ-HARKES, G.; VROMANS, M. E.; LANGEVELD, J. P. Immunohistochemical detection of prion protein in lymphoid tissues of sheep with natural scrapie. Journal of Clinical Microbiology, Washington, v. 34, n. 5, p. 1228-1231, 1996.

XU, L.; ZHANG, Z.; ZHOU, X.; YIN, X.; YANG, L.; ZHAO, D. Molecular cloning and polymorphism analysis of prion protein gene in Tan sheep of Ningxia, China. Gene, Amsterdam, v.485, p.102-105, 2011. 